\title{
AS TECNOLOGIAS DE COMUNICAÇÃO DO SÉCULO XXI E O MEIO AMBIENTE: A UTILIZAÇÃO DOS SATÉLITES ORBITAIS COMO INSTRUMENTOS PROBATÓRIOS NA VIOLAÇÃO DO MEIO AMBIENTE
}

\author{
Alfeu de Arruda Souza ${ }^{1}$ \\ Jerônimo Siqueira Tybusch ${ }^{2}$
}

\begin{abstract}
RESUMO
O Brasil é um país que apresenta uma das maiores coberturas vegetais e biodiversidade do planeta. Os recursos humanos por si só dos órgãos fiscalizadores são insuficientes para gerenciar e fiscalizar um territorio que possui dimensões continentais e que constantemente tem sofrido com a degradação e destruição de sua fauna e flora. Assim, diante da realidade do século XXI os órgãos de fiscalizções do meio ambiente estão cada vez mais utilizando-se das tecnologias de informação e dos sistemas de satélites como poderosas alternativas para fiscalizar os diversos biomas do país. O presente artigo visa abordar, através de uma pesquisa bibliográfica, a utilização das tecnologias de comunicação relacionadas ao mapeamento global e a geolocalização, a exemplo do sistema norte-americano de posicionamento global e dos satélites artificias de mapeamento, pelos órgãos governamentais e o papel que o software google earth poderá desempenhar como elemento de defesa do meio ambiente.
\end{abstract}

Palavras-chave: meio ambiente; satélites orbitais; google earth; geoposicionamento; sensoriamento remoto.

\section{INTRODUÇÃO}

A diversidade da fauna e flora são as maiores riquezas que o Brasil possui, no que tange a biodiversidade. O país possui territórios localizados tanto sob a linha do equador quanto sob o trópico de capricórnio, possuindo assim uma área de dimensões continentais e com diversos Biomas. No último século, o mundo presenciou o crescimento da população mundial e da consolidação do sistema capitalista, que juntos demandam enormes quantidades de recursos tanto minerais quanto naturais. Nesse contexto o mundo viu, conforme dados da WORD WILD FUND FOR NATURE (WWF)

\footnotetext{
${ }^{1}$ Acadêmico do Curso de Direito da Universidade Federal de Santa Maria (UFSM). Membro do Grupo de Pesquisa em Direito da Sociobiodiversidade - GPDS. E-mail: aarruda@inf.ufsm.br

${ }^{2}$ Doutor em Ciências Humanas pela Universidade Federal de Santa Catarina - UFSC. Mestre em Direito Público pela Universidade do Vale do Rio dos Sinos - UNISINOS. Graduado em Direito pela Universidade de Santa Cruz do Sul - UNISC. Professor Adjunto I da Universidade Federal de Santa Maria - UFSM. Professor Pesquisador I - UAB. Coordenador do Projeto "Justiça Ambiental em Redes Colaborativas: e-democracy e Ecologia Política na Sociedade Informacional Latino-Americana" contemplado com Auxílio Financeiro Edital Universal CNPq - 2011. Vice-líder do Grupo de Pesquisa em Direito a Sociobiodiversidade. E-mail: jeronimotybusch@ufsm.com
} 

III SEMINÁRII ECDLOGIA

POLÍTICA

disputa pela hegemonia global entre as duas superpotências que surgiram após o pósguerra, Estados Unidos e União Soviética, teve reflexos, além do campo cultural, no campo tecnológico. A utilização dos oceanos e do próprio espaço aéreo demandavam novas tecnologias que comportassem as novas necessidades de navegação, tanto para o campo civil, quanto o militar. Ao longo de diversos milênios, os mais diversos instrumentos de navegação foram utilizados, como a bússola e o astrolábio.

Entretanto, na década de 1970, viria a surgir a ferramenta mais engenhosa que a humanidade criou para localizar-se, o Sistema GPS. Todo o conhecimento de navegação, adquiridos ao longo da história, de forma indireta, foi consolidado em 1973, conforme Hurn (1989), no "Navigation Satellite with Time and Ranging / Global Positioning System”. Conhecido como "NAVSTAR/GPS - Navigation Satellite with Time And Ranging", ou, simplesmente, "GPS”, a criação do sistema foi subsidiada pelo Departamento de Defesa dos Estados Unidos, ao custo de bilhões de dólares, para fornecer a posição instantânea e a velocidade de um ponto.

O sistema GPS é composto, em seu todo, por três segmentos: o segmento espacial o qual é composto por satélites artificiais que emitem sinais eletromagnéticos; o segmento de controle, composto pelas estações terrestres que mantém os satélites funcionando; e o segmento dos usuários, composto pelos receptores que enviam os sinais aos satélites, os quais calculam a posição. Atualmente, 24 satélites (21 ativos, e os demais em reserva) estão distribuídos em 6 órbitas distintas, o que faz com que qualquer ponto da superfície terrestre tenha, próximo a ele, pelo menos 4 satélites acima da linha do horizonte. (LAGO; FERREIRA; KRUEGER, 2002). Ao contrário dos satélites utilizados pelos sistemas de comunicações, os satélites GPS não são geoestacionários, isto é, não permanecem numa posição fixa em relação à Terra, acompanhando a sua rotação.

Assim, qualquer usuário, munido de um aparelho receptor do Sistema GPS, poderá obter sua posição no espaço, a qual é calculada sob 3 dimensões. O receptor, a partir dos sinais emitidos pelos satélites, poderá determinar as distâncias entre o ele, e com no mínimo quatro satélites, as posições desses satélites. (CUGNASCA; PAZ, 2012, p. 10). Com isso, através do método da trilateração, o receptor poderá obter suas coordenadas geográficas (latitude e longitude) e sua altitude, e pode, ainda, determinar o instante atual, com altíssima precisão. 


\subsection{O Sistema GLONASS (Global Navigation Satellite System)}

O sistema GLONASS é o sistema de navegação por satélite da Federação Russa. Foi desenvolvido inicialmente, em 1976, pela extinta União Soviética como sistema militar concorrente ao GPS durante a guerra fria. O GLONASS, assim como o seu sistema concorrente, é constituído por três segmentos: O segmento espacial; o segmento de controle e o segmento de usuário. (WALTER; JUNIOR, 2004).

Enquanto o Sistema norte-americano de geolocalização atingiu o estágio de sistema completamente operacional em Março de 1994, o sistema russo apenas atingiu o mesmo status em março de 1995, e em decorrência da crise econômica russa e do decréscimo dos satélites em seus níveis orbitais ao longo dos anos, apenas voltou a ter plena cobertura global em Outubro de 2011. (RUSSIA, 2012). A difusão do sistema GPS foi maior na comunidade usuária internacional, devido à disponibilidade de informações, enquanto que as informações sobre o GLONASS tornaram-se acessíveis apenas após a dissolução da União Soviética, de modo que os dois sistemas passaram a ser considerados como complementares atualmente.

Enquanto a constelação definitiva do GPS é composta por 24 satélites (21 operacionais e 3 reservas ativos, distribuídos em seis planos orbitais), contendo em cada plano orbital 4 satélites em órbita quase circular, a uma altura de aproximadamente $20.200 \mathrm{~km}$ e inclinação de 55 graus em relação ao equador, a constelação do GLONASS possui 24 satélites dispostos em três planos orbitais. (LAGO; FERREIRA; KRUEGER, 2002, p. 39). Cada plano orbital do sistema Russo contém 8 satélites em órbita quase circular, com altura de aproximadamente $19.000 \mathrm{~km}$ e inclinação de 64,8 graus em relação ao equador.

De acordo com os especialistas no assunto

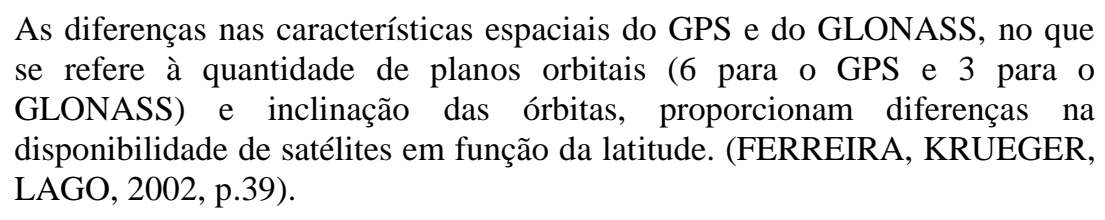

Assim, o sistema desenvolvido pela extinta União Soviética oferece melhor cobertura nas latitudes extremas enquanto que o GPS favorece as latitudes médias. 


\subsection{O software Google Earth e o Mapeamento do Globo Terrestre}

O Google earth é um software de visualização geoespacial. O programa utiliza de imagens de alta resolução da superfície terrestre, as quais, aliadas ao sistema GPS, fornecem um mapa do planeta de alta precisão e riquíssimo em detalhes. Surgido inicialmente como Earth Viewer, um produto da empresa Keyhole, Inc, foi adquirido em 2004 pela Google Inc., passando assim a fazer parte do portfólio de produtos da nova empresa. (GOOGLE, 2012). Em 2005, o Earth Viewier foi renomeado para Google Earth, sendo hoje um dos programas mais utilizados no mundo. O próprio nome "Keyhole" é uma homenagem aos satélites de reconhecimento KH, o sistema original de reconhecimento militar "olho-no-céu" que tem mais de 30 anos de idade.

As imagens do software são fornecidas em grande parte pela Empresa Digital Globe, proprietária do Satélite QUICKBIRD. Este foi projetado e construído em cooperação entre as empresas DigitalGlobe, Ball Aerospace \& Technologies Corp., Kodak e Fokker Space. A Ball Aerospace \& Technologies Corp. foi responsável pela construção do telescópio do sensor do satélite, de suas óticas de espelho bem como pelo veículo transportador. O plano focal, incluindo o CCD linear, instalações de compressão de imagem e eletrônica associada foram fornecidos pela Kodak. Como explicitou Kux; Pinheiro (apud PETRIE, 2002) em sua obra, os sensores CCD (Charge coupled device), que realizam a varredura eletrônica em fileira linear (pushbroom linear array), são flexíveis para visadas off-nadir até $25^{\circ}$, ao longo do terreno imageado. Kux; Pinheiro (apud EURIMAGE, 2002) relatam que o satélite foi colocado em órbita a partir da Vandenberg Air Force Base (Califórnia, EUA), em 18/10/2001, pelo lançador DELTA II.

O satélite QUICKBIRD é capaz de obter imagens em amplas faixas de imageamento, com cenas de 16,5 km x 16,5 km. Opera nos modos pancromático e multiespectral, nas faixas do visível e infravermelho próximo. (KUX; PINHEIRO, 2012). As imagens oferecidas pelo satélite sobre a superfície terrestre, possuem diferentes níveis de zoom e resolução e são voltadas ao uso comercial. No caso do Google Earth, as imagens obtidas, são enviadas para antenas que retransmitem o material para os laboratórios da Keyhole, a qual organiza as imagens e retransmite aos técnicos do Google, localizados na Califórnia. Através do uso destas imagens, o Google Earth possui uma série de recursos, que permitem desde girar uma imagem, 
III SEMINÁRII ECDLDGIA

POLÍTICA

E DIREITO NA AMÉRICA LATINA

obter as coordenadas geográficas de locais para visitá-los posteriormente, medir a distância entre dois pontos e até mesmo ter uma visão tridimensional de uma determinada localidade. No caso do Brasil, grande parte do território nacional já possui imagens em alta resolução.

\section{A UTILIZAÇÃO DOS SISTEMAS DE GEOLOCALIZAÇÃO E DE SENSORIAMENTO REMOTO PELOS ÓRGÃOS FISCALIZADORES ESTATAIS}

\subsection{A realidade ambiental do Brasil}

O Brasil, segundo o censo de 2010 do Instituto Brasileiro de Geografia e Estatística (IBGE) possui uma população de aproximadamente 190 milhões de pessoas e com perspectiva de crescimento positiva ao longo dos anos. (IBGE, 2012). Assim, a população nacional aliada à população mundial que conforme noticiado no G1 (G1, 2012), segundo dados da Organização das Nações Unidas é superior a 7 bilhões de habitantes, necessitam de uma quantidade de gigantesca de recursos naturais e energéticos para suprir as demandas da sociedade capitalista.

O Brasil é um país rico em biodiversidade, com diversos Biomas e milhares de espécies de animais e plantas. Como dispõe os estudiosos, percebe-se que

Segundo dados da Conservation International, estima-se que haja no território brasileiro cerca de $20 \%$ do número total de espécies do planeta. Com relação às plantas superiores, por exemplo, as estimativas mais aceitas sugerem que exista no Brasil entre 55 mil e 60 mil espécies (22 a 24\% do total mundial). Várias das espécies importantes para a economia mundial amendoim, castanha-do- Brasil, carnaúba, seringueira, guaraná, abacaxi e caju - são originárias do Brasil, além de inúmeras espécies madeireiras,medicinais, frutíferas, etc.

Estima-se, ainda, que a utilização dos componentes da biodiversidade (não só originária do Brasil) é responsável por cerca de $45 \%$ do PIB brasileiro, especialmente no que se refere aos negócios agrícolas (40\%), florestal (4\%), turístico $(2,7 \%)$ e pesqueiro $(1 \%)$. Produtos da diversidade biológica principalmente café, soja e laranja respondem por cerca de $30 \%$ das exportações brasileiras (dados de 1997). Isto demonstra a enorme interdependência dos países com relação à biodiversidade e economia.

Com relação à fauna, os dados brasileiros também são surpreendentes: Já foram descritas 524 espécies de mamíferos (131 endêmicos), 517 anfíbios (294 endêmicos), 1622 aves (191 endêmicos) e 468 répteis (172 endêmicos). Estima-se ainda que haja cerca de 3 mil espécies de peixes de água doce e de 




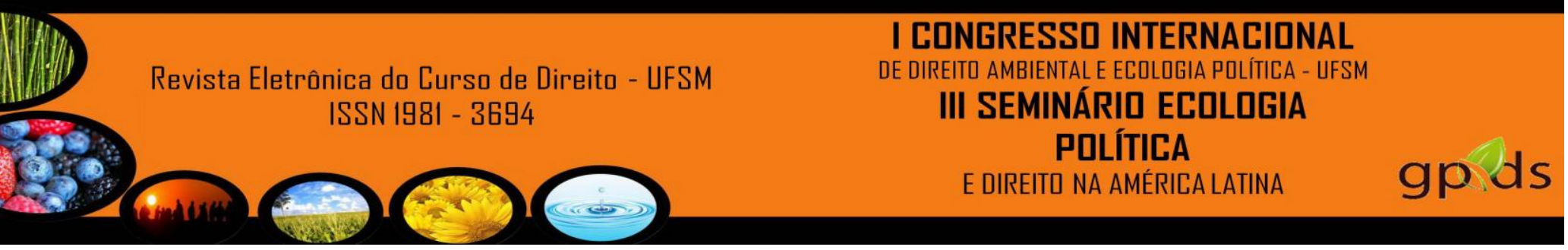

COMO foram tiradas as fotos do Google Earth? - Revista Abril. Disponível em: $<$ http://mundoestranho.abril.com.br/materia/como-foram-tiradas-as-fotos-dogoogle-earth> Acesso em: 24 fev. 2012.

COMO Surgiu o Google Earth? - Educação Adventista. Disponível em: <http://caj.educacaoadventista.org.br/3/tecnologia/26/como-surgiu-o-googleearth.html> Acesso em: 24 fev. 2012.

CUGNASCA, Carlos; PAZ, Sérgio. O Sistema de Posicionamento Global (GPS) e suas aplicações. São Paulo: USP. em:〈http://www.lps.usp.br/lps/arquivos/conteudo/grad/dwnld/ApostilaGPS.pdf> Acesso em: 24 fev. 2012.

FLORESTAL, Ambiente Florestal - O Olho Eletrônico do IBAMA Brasil Disponível em:<http://ambientes.ambientebrasil.com.br/florestal/programas_e_projetos/o_olho_ele tronico_do_ibama.htmlAcesso em: 26 jun. 2012.

G1 Mundo. Disponível em: < http://g1.globo.com/mundo/noticia/2011/10/populacaomundial-chega-7-bilhoes-de-pessoas-diz-onu.html> Acesso em: 26 jun. 2012

GOOGLE Earth and Maps Enterprise - Google. Disponível em:<http://www.google.com/enterprise/earthmaps/earthpro-compare.html> Acesso em: 24 fev. 2012.

HURN, J. GPS - A guide to the next utility. Trimble Navigation, Sunnyvale, Estados Unidos, 1989.

HYPSCIENCE Paraíso Madagascar - 615 espécies são encontradas na Ilha Disponível em:< http://hypescience.com/paraiso-madagascar-615-novas-especies-saoencontradas-ilha/> Acesso em: 26 jun. 2012.

INFOGPS, Imagens de satélite auxiliam ações de fiscalização contra desmatamento no Paraná- INFOGPS. Disponível em:< http://infogps.uol.com.br/blog/2008/03/04/imagens-de-satelite-auxiliam-acoes-defiscalizacao-contra-desmatamento-no-parana/> Acesso em: 26 Jun. 2012.

KUX, Hermann; PINHEIRO, Eduardo. Dados do Satélite QUICKBIRD para o mapeamento do uso e cobertura da terra numa seção da Mata Atlântica no Estado do Rio Grande do Sul. São José dos Campos: INEP, 2005. Disponível em:<http://marte.dpi.inpe.br/col/ltid.inpe.br/sbsr/2004/11.18.13.36/doc/4509.pdf>

Acesso em: 24 fev. 2012.

LAGO, I.; FERREIRA, L.;KRUEGER, C. GPS $\boldsymbol{E}$ GLONASS: Aspectos Teóricos e Aplicações Práticas. Curitiba: UFP, 2002.

NUSSBAUM, Ruth; VERÍSSIMO, Adalberto. Um resumo das florestas em países selecionados- Nota Técnica. São Paulo: Greenpeace, 2011. Disponível em: $<$ http 


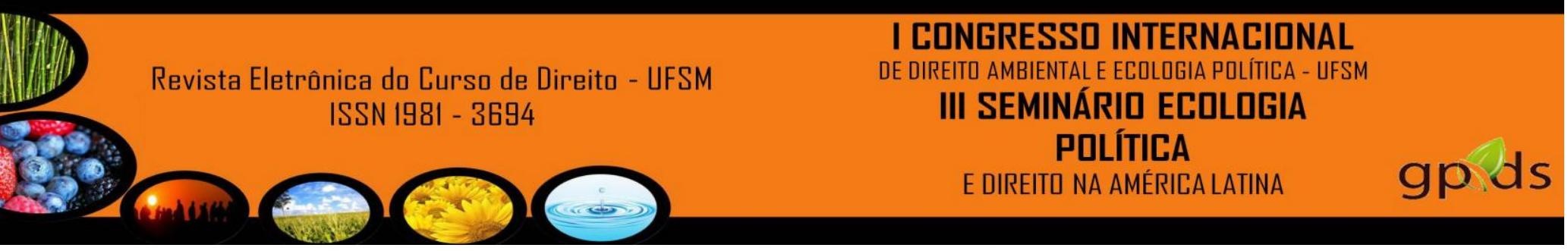

http://www.observatoriodoredd.org.br/site/pdf/Estudo_Florestas.pdf $>$ Acesso em: 26 Jun. 2012.

QUICKBIRD - Ministério da Agricultura, pecuária e Abstecimento. Disponível em:<http://www.sat.cnpm.embrapa.br/conteudo/quickbird.htm> Acesso em: 24 fev. 2012.

RUSSIA restores its orbital GLONASS - The Voice of the Russia. Disponível em:<http://english.ruvr.ru/2011/10/03/58065478.html> Acesso em: 24 fev. 2012.

WALTER, Fernando; JUNIOR, Ney L. Estudo e Implementação do Código CA para o Sistema Glonass da Federação Russa. São Paulo: ITA. 2004 Disponível em:<http://www.bibl.ita.br/xiencita/Artigos/ELE02.pdf> Acesso em: 24 fev. 2012.

WWF

Desmatamento.

Disponível

em:

$<$ http://www.wwf.org.br/natureza_brasileira/areas_prioritarias/amazonia1/ameacas_risc os_amazonia/desmatamento_na_amazonia/> Acesso em: 26 Jun. 2012. 